\title{
Exercise and Heart Failure. Relation of the Severity of the Disease to the Anaerobic Threshold and the Respiratory Compensation Point
}

\author{
Guilherme Veiga Guimarães, Giovanni Bellotti, Mauricio Wajngarten, Luzimar Teixeira, \\ José Franchini Ramires, Edimar Alcides Bocchi
}

São Paulo, SP - Brazil

Objective - To identify, the anaerobic threshold and respiratory compensation point in patients with heartfailure.

Methods - The study comprised 42 Men, divided according to the functional class $(F C)$ as follows: group I $(G I)-15$ patients in FC I; group II (GII) - 15 patients in FC II; and group III (GIII) - 12 patients in FC III. Patients underwent a treadmill cardiopulmonary exercise test, where the expired gases were analyzed.

Results - The values for the heart rate (in bpm) at the anaerobic threshold were the following: GI, 122 \pm 27 ; GII, $117 \pm 17$; GIII, 114 \pm 22 . At the respiratory compensation point, the heart rates (in bpm) were as follows: GI,

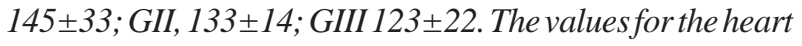
rates at the respiratory compensation point in GI and GIII showed statistical difference. The values of oxygen consumption $\left(\mathrm{VO}_{2}\right)$ at the anaerobic threshold were the

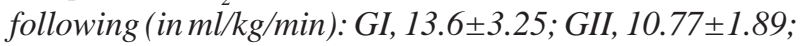
GIII, $8.7 \pm 1.44$ and, at the respiratory compensation point, they were as follows: GI, 19.1 \pm 2.2 ; GII, 14.22 \pm 2.63 ; GIII, $10.27 \pm 1.85$.

Conclusion - Patients with stable functional class I, II, and III heart failure reached the anaerobic threshold and the respiratory compensation point at different levels of oxygen consumption and heart rate. The role played by these thresholds in physical activity for this group of patients needs to be better clarified.

Key words: heart failure, exercise, oxygen consumption

Instituto do Coração do Hospital das Clínicas - FMUSP

Mailing address: Guilherme Veiga Guimarães - Rua Dr. Baeta Neves, 98 - $05444-$ 050 São Paulo, SP, Brazil

Received on $1 / 4 / 99$

Accepted on 6/16/99
Dyspnea and fatigue during exercise often limit patients with heart failure, even when asymptomatic at rest. Therefore, patients with heart failure, as compared with healthy individuals, have a lower tolerance for physical exercise and more marked metabolic and respiratory responses ${ }^{1,2}$ to the same intensity of work associated with muscle functional and structural changes ${ }^{3}$.

Even though controversial, some studies ${ }^{4-6}$ have shown beneficial effects of exercise training on the quality of life and on the symptoms of patients with this syndrome. To guide physical activity, the use of percentages of maximum oxygen consumption ${ }^{7-9}$ or of maximum heart rate ${ }^{10-12}$ for patients with heart failure has been recommended. Therefore, there is no uniformity regarding the use of indices for the recommended intensity of physical activity for these patients. This orientation does not take into consideration the severity of the clinical situation and its relation to training intensity, which may be inadequate due to generalization of the percentages and may jeopardize the beneficial effects of physical activity.

Our study aimed to identify, through the cardiopulmonary exercise test, the anaerobic threshold and the respiratory compensation point, which are indices used to guide physical activity for healthy people. We also aimed to identify the relationship of these indices to the severity of the disease in patients with NYHA functional class I, II and III heart failure, who were referred to the outpatient care unit of the heart transplantation group at the Instituto do Coração of the Hospital das Clínicas - FMUSP.

\section{Methods}

We studied 42 males with heart failure, 30 of whom had idiopathic dilated cardiomyopathy, 3 had Chagas' disease, 4 had ischemic cardiomyopathy, and 5 had hypertrophic cardiomyopathy without obstruction in the phase of significant dilation. The patients were sequentially assessed from June to December 1996 and were divided into gro- 
ups according to the NYHA functional class criteria (table I). The groups were constituted as follows: Group I: $n=15$, $\mathrm{VO}_{2 \text { peak }}=23.03 \mathrm{ml} / \mathrm{kg} / \mathrm{min}$; Group II: $\mathrm{n}=15, \mathrm{VO}_{2 \text { peak }}=16.75 \mathrm{ml} /$ $\mathrm{kg} / \mathrm{min}$; and Group III: $\mathrm{n}=12, \mathrm{VO}_{2 \text { peak }}=11.57 \mathrm{ml} / \mathrm{kg} / \mathrm{min}$.

Some patients were excluded from the study due to the following reasons: impossibility of reaching the respiratory compensation point, impossibility of identifying the thresholds, presence of orthopedic problems or noncardiovascular restrictions to exercise, atrial fibrillation, cachexia, submaximum test $\left(\mathrm{R}\left(\mathrm{VCO}_{2} / \mathrm{VO}_{2}\right)<1.05\right)^{13}$, interruption of the test due to submaximum limitation caused by peripheral fatigue or to significant changes in the ECG during exercise. No woman was included in the study because of the small number of women evaluated during the period of the study.

All patients with heart failure referred for a cardiopulmonary exercise test were regularly followed up in the outpatient care unit of the heart transplantation team at INCOR. These patients were acquainted with the technique and the study protocol. The cardiopulmonary exercise test was performed within a week, and the patients were instructed to avoid beverages with caffeine, not to smoke on the day of the test, to maintain their daily activities, and not to stop taking their medication. All patients were assessed in a temperature-controlled environment $\left(21-23^{\circ} \mathrm{C}\right)$, at least two hours after a meal, while on their medication (digitalis, diuretics, and angiotensin-converting enzyme inhibitors). All assessments were part of the clinical procedures approved by the Committee on Ethics at INCOR, and all patients gave their previous consent to the publication of scientific data.

Initially, all patients underwent a resting ECG, with the 12 standard leads, and also a treadmill stress test with continuous monitoring of the ECG, of the blood pressure through the auscultatory method, and of the ventilation and gaseous changes. The test was performed with a programmed treadmill (Q65 model, Quinton, Quinton Instrument Co., Seattle, Washington, USA) according to a modified Naugthon protocol ${ }^{14}$. Two minutes after standing at rest, all patients were encouraged to exercise with increasing intensity until the symptoms (fatigue or dyspnea) prevented them from continuing the test. A cell with zirconium was used to measure the expired oxygen $\left(\mathrm{O}_{2}\right)$, infrared absorption was used to measure the carbon dioxide $\left(\mathrm{CO}_{2}\right)$, and a pneumotachograph was used to measure the air flow. The metabolic analyzer combined data from the gas analyzers and the pneumotachograph. Measurements were obtained with the patients standing, resting, exercising, and in the recovery period, through the use of a respiratory device consisting of a mouthpiece, a nose clip, and a low resistance valve with two vias (Hans-Rudolph; dead space of $100 \mathrm{~mL}$ ). Ventilatory data and those of the gaseous changes were obtained at each respiratory cycle, using a computerized system (CAD/Net 2001 model, Medical Graphics Corporation); analysis of data collected was performed through the mean of the intervals at each 60 seconds. Respiratory variables were analyzed to determine the ventilatory thresholds. Peak oxygen consumption $\left(\mathrm{VO}_{2 \text { peak }}\right)$ was considered the highest $\mathrm{VO}_{2}$ reached during the test (the criteria for determining $\mathrm{VO}_{2}$ max were observed ${ }^{15}$, and it was used as an index of maximum physical capacity for each individual ${ }^{16}$.
From data obtained in the cardiopulmonary exercise test, the anaerobic threshold and the respiratory compensation point were determined through the analysis of the expired gases. The anaerobic threshold was determined at the moment when the levels of the ratio between ventilation and $\mathrm{VO}_{2}$ (ventilation/ $/ \mathrm{VO}_{2}$ ) and the oxygen partial end-tidal pressure $\left(\mathrm{Pet}_{2}\right)$ reached minimum values before starting to rise, and through the nonlinear increment of the ratio between carbon dioxide production per minute $\left(\mathrm{VCO}_{2}\right)$ and the $\mathrm{VO}_{2}{ }^{11,17,18}$. The respiratory compensation point was determined at the moment when the levels of the ratio between ventilation and $\mathrm{VCO}_{2}$ (ventilation/ $/ \mathrm{VCO}_{2}$ ) reached minimum values before starting to rise and the carbon dioxide partial end-tidal pressure $\left(\mathrm{Pet} \mathrm{CO}_{2}\right)$ reached maximum levels before starting to decrease ${ }^{13,14}$.

Data were presented in the form of mean \pm standard deviation. Data concerning the characteristics of the sample and comparison of the programs prescribed for the groups underwent the analysis of variance (ANOVA) with one one way and a statistical significance level of $p<0.05$. When there was significance, the post hoc analysis of Bonferroni was performed. To compare prescription data in each group studied, the Student $t$ test for paired data was used, with a statistical significance level of $\mathrm{p}<0.05$.

\section{Results}

Table I shows the patients with heart failure divided into groups according to the NYHA functional classes; the mean values of the variables show the homogeneity between the groups of patients.

The mean values and the standard deviation of the maximum heart rate in groups I, II, and III, were, respectively (in bpm): $161 \pm 32 ; 155 \pm 15$; and $134 \pm 26^{*}, * *$. The mean values and the standard deviation of the peak oxygen consumption $\left(\mathrm{VO}_{2 \text { peak }}\right)$ in groups I, II, and III, were, respectively (in $\mathrm{mL} / \mathrm{kg}$ / $\min ): 23.03 \pm 2.75 ; 16.75 \pm 1.75 *$; and $11.57 \pm 1.95 * * * ; * \mathrm{p}<0.05$ different from group I and $* * \mathrm{p}<0.05$ different from group II. The $\mathrm{VO}_{2 \text { peak }}$ index of physical capacity showed a significant difference between patients in functional classes I, II, and III. This behavior was not observed in the values of maximum

\begin{tabular}{|lccc|}
\hline \multicolumn{4}{|c|}{ Table I - Characteristics of the patients with NYHA functional } \\
class I, II, and III heart failure
\end{tabular}


heart rate between groups I and II; a significant difference occurred only in group III in the most critically ill patients.

The values of oxygen consumption and heart rate at the aerobic threshold $\left(\mathrm{VO}_{2 \mathrm{at}}\right.$ and $\mathrm{HR}_{\mathrm{at}}$, respectively) are shown in table II, and the percentages of $\mathrm{VO}_{2 \text { peak }}\left(\% \mathrm{VO}_{2 \text { peak }}\right)$ and maximum heart rate are shown in figures 1 and 2 . We noticed significant differences when comparing the $\mathrm{VO}_{2 \mathrm{at}}$ of group I with II and I with III; the same when comparing the percentage of $\mathrm{VO}_{2 \text { peak }}$ of group I with III and II with III; the same when comparing the percentage of the maximum heart rate of group I with III.

Table II shows the values of $\mathrm{VO}_{2}$ and of heart rate at the respiratory compensation point; we observed a significant difference of $\mathrm{VO}_{2}$ between the groups and of heart rate when comparing group I with III. Figures 1 and 2 illustrate the percentage of $\mathrm{VO}_{2 \text { peak }}$ and the percentage of maximum heart rate at the respiratory compensation point in the

\begin{tabular}{|c|c|c|c|}
\hline \multicolumn{4}{|c|}{$\begin{array}{l}\text { Table II - Oxygen consumption and heart rate at the anaerobic } \\
\text { threshold and at the respiratory compensation point of patients } \\
\text { with NYHA functional class I, II and III }\end{array}$} \\
\hline Variables & $\begin{array}{l}\text { Functional } \\
\text { Class I } \\
(\mathrm{n}=15)\end{array}$ & $\begin{array}{l}\text { Functional } \\
\text { Class II } \\
(\mathrm{n}=15)\end{array}$ & $\begin{array}{l}\text { Functional } \\
\text { Class III } \\
(\mathrm{n}=12)\end{array}$ \\
\hline $\mathrm{VO}_{2}$ at & $13,6 \pm 3,25$ & $10,77 \pm 1,89 *$ & $8,7 \pm 1,44 *$ \\
\hline$\% \mathrm{VO}_{2}$ peak & $58 \pm 11$ & $64 \pm 11$ & $76 \pm 11 *, * *$ \\
\hline HRat & $122 \pm 27$ & $117 \pm 17$ & $114 \pm 22$ \\
\hline$\%$ HRmax & $73 \pm 6$ & $76 \pm 13$ & $84 \pm 6 *$ \\
\hline $\mathrm{VO}_{2} \mathrm{rcp}$ & $19,1 \pm 2,2$ & $14,22 \pm 2,63 *$ & $10,27 \pm 1,85 *, * *$ \\
\hline$\% \mathrm{VO}_{2}$ peak & $82 \pm 11$ & $84 \pm 11$ & $88 \pm 6$ \\
\hline HRrcp & $145 \pm 33$ & $133 \pm 14$ & $123 \pm 22 *$ \\
\hline$\%$ HRmax & $90 \pm 7$ & $86 \pm 9$ & $90 \pm 6$ \\
\hline \multicolumn{4}{|c|}{$\begin{array}{l}\mathrm{VO}_{2} \text { at- oxygen consumption at the anaerobic threshold in } \mathrm{mL} / \mathrm{kg} / \mathrm{min} \text {; } \\
\mathrm{HRat} \text { - heart rate at the anaerobic threshold in bpm; } \mathrm{VO}_{2} \mathrm{rcp}-\text { oxygen } \\
\text { consumption at the respiratory compensation point in } \mathrm{mL} / \mathrm{kg} / \mathrm{min} \text {; } \\
\text { HRrcp- heart rate at the respiratory compensation point in bpm, * different } \\
\text { from group I }(\mathrm{p}<0.05) ; * * \text { different from group II }(\mathrm{p}<0.05) \text {. }\end{array}$} \\
\hline
\end{tabular}

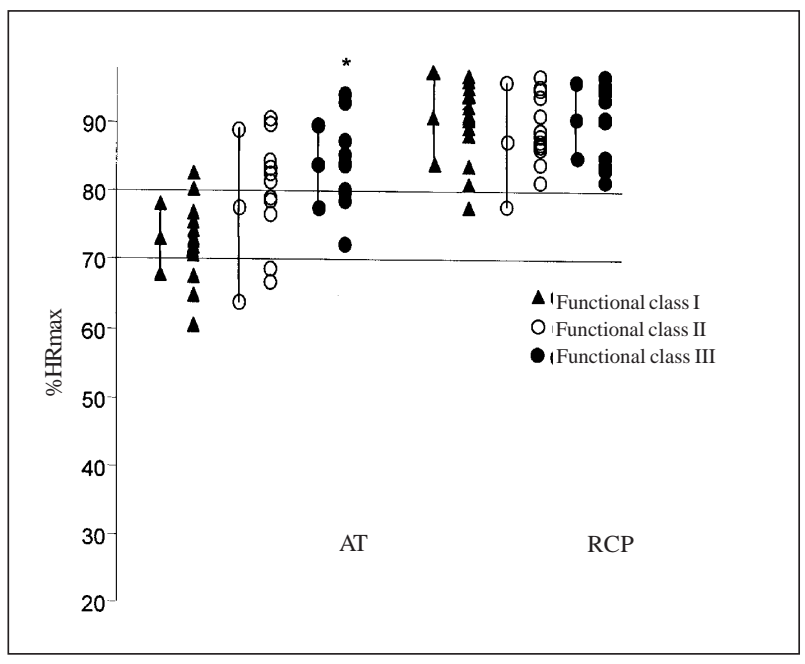

Fig. 1 - Percentage of the maximum heart rate (\%HRmax) in the anaerobic threshold (AT) and respiratory compensation point (RCP) of all patients with heart failure (HF) in functional classes I, II and III.

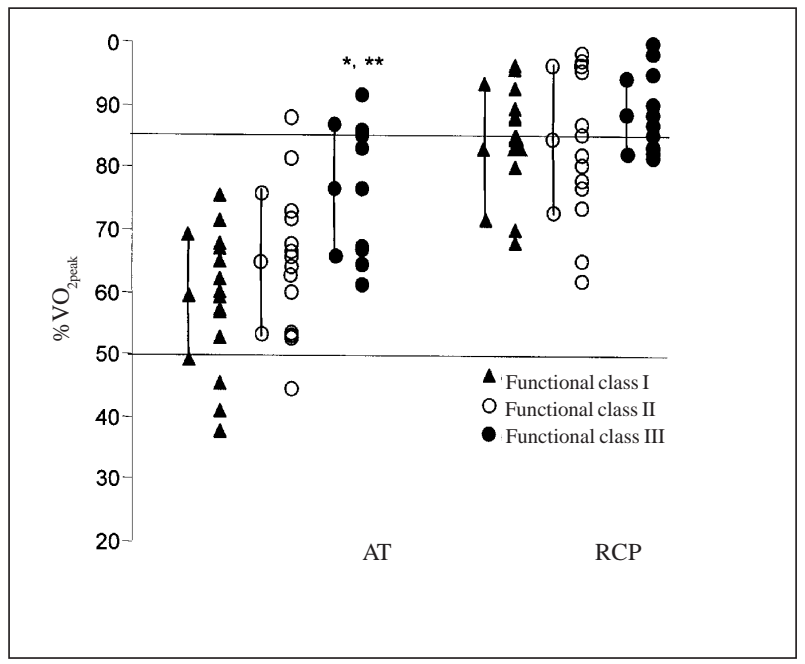

Fig. 2 - Percentage of maximum oxygen consumption $\left(\% \mathrm{VO}_{2 \text { peak }}\right)$ in the anaerobic threshold (AT) and respiratory compensation point (RCP) of all patients with heart failure (HF) in functional classes I, II and III.

groups of patients with NYHA functional class I, II, and III heart failure; groups I, II, and III had no significant differences among them.

\section{Discussion}

Our results show that in patients with heart failure classified according to the NYHA functional classes, the anaerobic threshold and the respiratory compensation point may differ in regard to different levels of oxygen consumption and heart rate. Therefore, an assessment using the cardiopulmonary exercise test with the determination of the thresholds, in programming the physical activity, may be more beneficial for evaluating the cardiopulmonary capacity of this group of patients than conventional methods of physical activity prescription.

Previous studies in patients with heart failure used the percentages of maximum heart rate $(70 \%$ to $80 \%)$ or of peak oxygen consumption ( $50 \%$ to $85 \%)^{4-6}$, based on the recommendations of the American Heart Association ${ }^{19}$, as guides when prescribing physical exercises to individuals with cardiovascular diseases. The aim was to evaluate if physical conditioning would improve in the short- and long-term the functional capacity and the quality of life in heart failure.

In our study, however, the indices of intensity of suggested physical activity, such as the anaerobic threshold and the respiratory compensation point, varied from $73 \%$ to $90 \%$ of the maximum heart rate and from $59 \%$ to $88 \%$ of the $\mathrm{VO}_{2 \text { peak }}$; they do not corroborate those reported in the literature. In patients with more severe heart failure, the percentages of the anaerobic threshold and of the respiratory compensation point ranged from $84 \%$ to $90 \%$ of the maximum heart rate and from $75 \%$ to $88 \%$ of the $\mathrm{VO}_{2 \text { peak }}$. The use of previously established indices of intensity may not take into consideration the individual metabolic and physical characteristics of those attending or starting a physicalconditioning program. Most of the time, one may underes- 
timate or overestimate the guidelines for physical activity for healthy or ill individuals.

When the values of the maximum heart rate in the groups of patients in functional classes I, II, and III were compared, we observed significant differences. For the values of heart rate in the anaerobic threshold, an index considered representative during the exercise in the transition of the aerobic to the compensated anaerobic metabolism, no significant differences between the groups were observed. On the other hand, in the respiratory compensation point, which is the exercise threshold which the buffer system and sodium bicarbonate do not manage to compensate for the lactate produced by the increase in the amount of exercise, we noted a significant difference in group III, which comprised the most critically ill patients. The differences in heart rate in the patients with heart failure according to the functional classes may be explained by muscle factors and by the chronotropic, flow and sympathetic stimulation dysfunctions. The chronotropic dysfunction causes the heart to act as if it were denervated in the control of the heart rate in heart failure. One of the probable causes is the reduction in the number of receptors of cardiac norepinephrine and a total increase in serum norepinephrine, probably due to an increase in neural sympathetic activity; this is more accentuated according to the severity of the disease ${ }^{20}$. Another mechanism proposed to explain this behavior is that patients with heart failure have changes in muscle activity, such as an increase in type II fibers, especially those of the subtype IIb, which are of rapid contraction and depend almost entirely on anaerobic metabolism for energy production. A probable reduction in the type I slow contraction fibers that contain a high concentration of mitochondrial enzymes necessary to sustain aerobic metabolism ${ }^{21-23}$ is another suggested mechanism. In addition, a small increase in peripheral blood flow during submaximum and maximum exercise and the decrease in muscle mass cause metabolic thresholds to be reached more precociously and a proximity between them to occur, stressing the severity of the disease (fig. 3).

Values of oxygen consumption in exercise peak, at the anaerobic threshold and at the respiratory compensation point are significantly different among the groups. A decrease in the peak oxygen consumption of patients correlates with the severity of the disease ${ }^{24}$. According to Fick's law, the only factors determining oxygen consumption are cardiac output and peripheral oxygen extraction. In patients with heart failure, impairment in cardiac output during exercise caused by an inability of the heart to maintain blood flow adequate for metabolic needs, increases oxygen extraction at rest and progressively until the maximum exercise is reached ${ }^{4}$. With aggravation of the disease, reduction in blood flow causes the threshold of oxygen extraction to be reached rapidly in submaximum loads, increasing lactate production and, therefore, forestalling

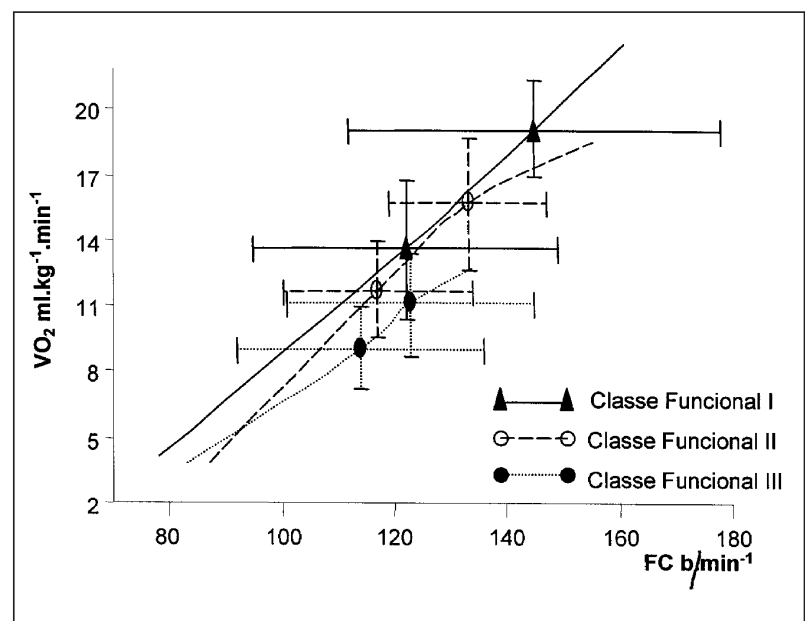

Fig. 3-Mean values of oxygen consumption $\left(\mathrm{VO}_{2}\right)$ and of heart rate $(\mathrm{HR})$ of patients with heart failure (HF) in functional classes I, II and III. Data obtained during exercise: anaerobic threshold (AT) and respiratory compensation point (RCP).

and approximating the thresholds in this group of patients with heart failure (fig. 3).

A limited number of patients were studied according to the functional classes in each group. Tests were performed by different teams and in different periods of time but under the same guidelines. This may influence the time of exercise and the $\mathrm{VO}_{2 \text { peak }}{ }^{25}$; the thresholds, however, do not depend on motivation ${ }^{26}$.

The intensity of physical activity may define whether a patient will obtain beneficial results ${ }^{7}$. In healthy people ${ }^{27,28}$ and, presumably, in patients with heart failure, the major physical, metabolic and respiratory benefit seems to lie in moderate to strong aerobic activities, i.e., between the thresholds ${ }^{29}$. Identifying the anaerobic threshold and the respiratory compensation point and their relation to the severity of the disease in patients with stable heart failure may be important in programs for physical conditioning ${ }^{30}$. However, $\mathrm{VO}_{2}$ and heart rate in the anaerobic threshold and in the respiratory compensation point, as they are individual, may be more representative variables of improvement and also better indicators to guide physical activity ${ }^{31}$.

In conclusion, patients with stable heart failure in functional classes I, II, and III reach the anaerobic threshold and the respiratory compensation point at distinct levels of oxygen consumption and heart rate. These results may be beneficial in programming the management of heart failure, such as when prescribing physical activity. The role thresholds play in physical activity needs to be better clarified in this group of patients.

\section{Acknowledgments}

We thank Rejane Augusta Astolpho, Paulo Roberto Santos Silva, Amilcar Oshiro Mocelin and Fernando Bacal for their support. 


\section{References}

1. Koike A, Hiroe M, Adachi H, et al. Anaerobic metabolism as na indicator of aerobic function during exercise in cardiac patients. J Am Coll Cardiol 1992; 20: 120-6.

2. Weber KT, Kinasewitz GT, Janicki JS, et al. Oxygen utilization and ventilation during exercise in patients with chronic cardiac failure. Circulation 1982; 65: 1213-23.

3. Metra M, Faggiano P,D“Aloia A, et al. Mild hemodynamic imparied in patients with heart failure and reduced functional capacity. J Am Coll Cardiol 1997; 29: 423"

4. Conn EH, Willians RS, Wakace AG. Exercise responses before and after physical conditioning in patients with severely depressed left ventricular function. Am J Cardiol 1982, 49: 296-300.

5. Mckelvie RS, Teo KK, McCartney N, et al. Efeitos do exercício físico em pacientes com insuficiência cardíaca congestiva: Uma revisão crítica. J Am Coll Cardiol (ed. bras) 1995; 1: 300-8

6. Uren NG, Lipkin DP. Exercise training as therapy for chronic heart failure. Br Heart J 1992; 67: 430-3.

7. Sullivan MJ, Higginbotham MB, Cobb FR. Exercise training in patients with severe left ventricular dysfunction. Hemodynamic and metabolic effects. Circulation $1988 ; 78: 506-15$.

8. Meyer K, Görnandt L, Schwaibold M, et al. Predictors of response to exercise training in severe chronic congestive heart failure. Am J Cardiol 1997; 80: 56-60.

9. Willenheimer R, Erhardt L, Cline C, Rydberg E, Israelsson B. Exercise training in heart failure improve quality of life and exercise capacity. Eur Heart J 1998; 19 : 774-81.

10. Jetté M, Heller R, Landry F, Blumchen G. Randomized 4-week exercise program in patients with impaired left ventricular function. Circulation 1991, 84: 1561-7.

11. Coats AJS, Adamopoulos S, Radaelli A, et al. Controled trial of physical training in congestive heart failure. exercise performance, hemodynamics, ventilation and autonomic function. Circulation 1992, 85: 2119-31.

12. Dziekan G, Myers J, Goebbels U, et al. Effects of exercise training on limb bllod flow in patients with reduced ventricular function. Am Heart J 1998; 136: 22-30.

13. Katz SD, Berkowitz R, LeJemtel TH. Anaerobic threshold detection in patients with congestive heart failure. Am J Cardiol 1992; 15: 1565-69.

14. Patterson J, Naughton J, Pietras RJ. Treadmill exercise in assessment of functional capacity of patients with severe left ventricular disease. Am J Cardiol 1972; 30: 757-62.

15. Wasserman K, Hausen JE, Sue DY, Whipp BJ, Casaburi R. Principes of Exercise Testing and Interpretation. $2^{\text {nd }}$ ed. Phyladelphia: Lea \& Febiger, 1994.

16. Bocchi EA, Guimarães GV, Moreira LF, et al. Peak oxygen consumption and resting left ventricular ejection fraction changes after cardiomyoplasty at 6 months follow-up. Circulation 1995; 92(suppl II):

17. Skinner JS, McLellan TH. The Transition from Aerobic to Anaerobic Metabolism. Res Quarterly Exerc and Sport 1980; 51: 234-48.

18. Bhambhani Y, Singh M. Ventilatory thresholds during a graded exercise test. Respiration 1985; 47: 120-8.

19. American Heart Association: exercise testing and training of individuals with heart disease or at high risc for its development. A Handboock for Physicians. Dallas, American Heart Association 1975:

20. Hammond HK, Froelicher VF. Normal and abnormal heart rate responses ro exercise. Prog Cardiovas Diseases 1985; XXVII: 271-96.

21. Piña IL, Fitzpatrick JT. Exercise and heart failure. Chest 1996; 110: 1317-27.

22. McConnell TR. Exercise intolerance in congestive heart failure: a lesson in exercise physiology. J Cardiopulmonary Rehabil 1997; 17: 217-21.

23. Harrington D, Anker SD, Chua TP, et al. Skeletal muscle function and its relation to exercise tolerance in chronic heart failure. J Am Coll Cardiol 1997; 30: 1758-64.

24. Mancini DM,Eisen H, Kussmaul W, et al. Value of peak exercise oxygen consumption for optimal of cardiac transplantation in ambulatory patients with heart failure. Circulation 1991; 83: 778-86.

25. Clark AL, Poole-Wilson PA, Coats AJS. Effects of motivation of the patiente on indices of exercise capacity in chronic heart failure. Br Heart J 1994; 71: 162-5.

26. Cohen-Solal A, Aupetti JF, Gueret P, Kolsky H, Zannad F. Can anaerobic threshold be used as na end-point for therapeutic trials in heart failure? Eur Heart J 1994; 15: 236-41.

27. Rondon MUPB, Forjaz CLM, Nunes N. Comparação entre a prescrição de intensidade de treinamento físico baseada na avaliação ergométrica convencional e na ergoespirometria. Arq Bras Cardiol 1998; 70: 159-66.

28. Kalil LMP, Barretto ACP, Guimarães GV, et al. Capacidade física em idosos submetidos a programa de condicionamento físico. Rev Soc Cardiol ESP 1996; 6: 68-75.

29. Silva PRS, Yasbek P, Romano A, Cordeiro JR, Battistella L. Ergoespirometria computadorizada ou calorimetria indireta: um método não-invasivo de crescente valorização na avaliação cardiorrespiratória ao exercício - parte I. Âmbito Med Despor 1997; 29: 3-10.

30. Guimarães G,BocchiEA,MoreiraLF, etal.Efeitodocondicionamentofísico após cardiomioplastia: para tratamento de insuficiência cardíaca refratária. Anais do LI Congresso Brasileiro de Cardiologia. Rio de Janeiro: Arq Bras Cardiol 1995; 65: 95.

31. Silva PRS, Yasbek P, Romano A, Cordeiro JR, Battistella L. Ergoespirometria computadorizada ou calorimetria indireta: um método não-invasivo de crescente valorização na avaliação cardiorrespiratória ao exercício - parte II. Âmbito Med Despor 1997; 30: $19-32$ 